\title{
Toxicity of car exhausts and opportunity for suicide: comparison between Britain and the United States
}

\author{
RONALD V CLARKE ${ }^{1}$ AND DAVID LESTER ${ }^{2}$ \\ From the Department of Criminal Justice, ${ }^{1}$ Temple University, Philadelphia, Pennsylvania 19122, and Stockton \\ State College, 2 Pomona, New Jersey 08240, USA.
}

SUMmaRY The rate of car exhaust suicides in the United States has declined following the introduction of emission controls in the mid-1960s, though not as much as the decline in CO emitted by cars. In Britain, where emission controls have not been introduced, the rate of these suicides, initially much lower than in the United States, has greatly increased since the beginning of the 1970s and is now about double that of the United States. This rise cannot be explained simply on the basis of an increase in the opportunities for suicide as represented by an increase in the number of cars but may be due to increased knowledge of the method. While these results are interpreted as generally supporting the potential for opportunity-reducing preventive measures, they also demonstrate that much more research is needed into the complex nature of the opportunity structure for suicide.

Despite much earlier controversy, it now seems established that the $35 \%$ decline in the suicide rate in England and Wales between 1963 and 1971 was due largely to progressive reductions in the carbon monoxide content of the domestic gas supply..$^{1-4}$ Gas detoxification came about in two sequential stages resulting, first, from the introduction of new gas manufacturing processes and, later, from the conversion to natural gas from the North Sea. From being the single most popular method of suicide, accounting at its height for more than half of all such deaths in the country, suicide by domestic gas was all but eliminated by 1978 when conversion to natural gas was completed.

Other explanations for the decline rest on a much less secure basis of evidence. For example, Bagley's 5 suggestion that it was due to the activities of the Samaritans was later withdrawn ${ }^{6}$ when Barraclough et al were unable to replicate his findings using an improved research design. The suggestion of Sainsbury $e t$ a $\boldsymbol{f}^{\boldsymbol{\beta}}$ that the decline in suicide was due to improved social well-being in England and Wales during the period in question is poorly supported by their data and is not consistent with the fact that unemployment rates increased by $50 \%$ during the same period. ${ }^{3}$

The principal objection to the reduced toxicity hypothesis is that, on finding that they could no longer use gas, people intent on suicide would have turned to some other means. But this ignores the very real advantages of domestic gas over many other methods-it is painless, clean, easy and requires relatively little courage or preparation-as well as the frequently ambivalent or transitory nature of the motivation to commit suicide. Whether these motivations are translated into effective action will depend on the opportunities for suicide available to the individual concerned. At a broader societal level, rates of suicide will therefore be partially dependent on the society's "opportunity structure" for suicide.

Natural experiments, such as that resulting from the actions of the British gas authorities which alter the opportunity structure for suicide, occur rarely, but a further example is provided by the introduction of exhaust emission controls on automobiles in the United States. These controls were intended to reduce levels of air pollution by requiring new vehicles to be fitted with devices to remove, or greatly reduce, the toxic agents in exhaust gases, in particular hydrocarbons, nitrogen oxides, and carbon monoxide. It is the latter gas which is fatal if released in sufficiently high concentrations into a confined space such as the passenger compartment of a car or a closed garage.

Emission controls were introduced by the federal government for all new cars in 1968 though some states particularly troubled by air pollution, such as California, had imposed them a few years earlier. The federal standards have become progressively stricter so that the exhaust gases of the newest cars are required to be much cleaner than those of cars brought onto the road in the early years of emission controls. 
For example, the $\mathrm{CO}$ content of the exhaust gas of 1984 cars had to be reduced to only $4 \%$ of that of pre-control cars, whereas the corresponding figure for 1968 cars was $40 \%$. Emission controls have made it more difficult to commit suicide with newer cars, and reports have recently appeared in the literature of failed suicide attempts as a consequence of the reduced CO content of exhaust gases.9,10

In this paper we examine the overall effect of emission controls on what has been a favoured method of suicide in the United States and compare rates of car exhaust suicides with those in Britain (viz, England and Wales and Scotland) where emission controls have yet to be introduced. For both countries, the measure of opportunity for car exhaust suicide was the number of cars in use; for the United States, however, an "adjusted" measure of cars in use was also calculated to take account of the progressive effect of emission controls in reducing the toxicity of the exhaust gases of newer cars.

\section{Data sources}

For the United States, the numbers of motor vehicle exhaust suicides were obtained for 1950-81 from the annual volumes of the Vital statistics of the United States and for 1982-84 from unpublished data held by the National Center for Health Statistics. For Britain, directly comparable annual data were available only for more recent years, and thus data for the slightly broader category of "suicides by poisoning with other gases" (in 1979, 95\% of suicides by this means were by car exhaust gases) were obtained for Scotland from the Annual report of the Registrar General for Scotland (1950-82) and from the Statistical review of England and Wales, Part IB, Medical (1950-73) and the Mortality statistics, DH4 (1974-82) for England and Wales. Suicide figures for 1983-4 were supplied directly by the OPCS and by the Registrar General of Scotland. Population figures for the United States were obtained from the Statistical abstract of the United States: 1986 and for Britain ("mid-year estimates") from volumes of the Annual abstract of statistics. The numbers of "cars and vans registered in private use" in Britain were also obtained from the Annual abstract of statistics; for the United States, figures for "cars in operation" were obtained from Facts and figures, the annual reports of the Motor Vehicle Manufacturers Association (MVMA).

\section{“Adjusted" measure of cars in the United States}

The MVMA figures for "cars in operation" are listed by year of manufacture or, more strictly, by model year. This, together with the CO emission standards holding for each year, permits calculation of an "adjusted" measure of cars in operation which takes account of the progressively reduced toxicity of cars brought onto the road from 1968 onwards. The emission standards, also listed in the MVMA annual reports, are as follows: 1968-71, CO content of exhaust gases of all new cars to be reduced to $40 \%$ of pre-control levels (ie, before 1968); for 1972-74 to $33 \%$; for $1975-78$ to $18 \%$; for 1980 to $8 \%$; and for $1981-84$ to $4 \%$. The effect of applying these standards to cars in operation would be such, for example, that each 1981 car would contribute only $4 \%$ as much to the "adjusted" 1981 measure of cars in operation as each pre-control car. To illustrate the procedure involved, the calcuation for 1981 is shown in the table.

\begin{tabular}{lccc}
\hline Model year & $\begin{array}{l}\text { Cars in operation } \\
\text { in 1981 ("000s) }\end{array}$ & Co standard \% & $\begin{array}{l}\text { Adjusted measure } \\
\text { cars in operation } \\
\text { ("O00s) }\end{array}$ \\
\hline Pre-68 & 7920 & 100 & 7920 \\
$1968-71$ & 15171 & 40 & 6068.40 \\
$1972-74$ & 23299 & 33 & 7688.67 \\
$1975-79$ & 45491 & 18 & 8188.38 \\
1980 & 8818 & 8 & 705.44 \\
1981 & 5140 & 4 & 205.60 \\
All models & 105839 & & 30776.49 \\
\hline
\end{tabular}

It can be seen that the "adjusted" measure of cars in operation for 1981 was 30776490 compared with the actual number of about 105839000 cars. In calculating adjusted measures, it was not possible to take account of the fact (mentioned above) that for a few years before the introduction of nationwide emission standards in 1968, some states had previously introduced controls or that some new models carried emission controls before they were required to do so.

\section{Findings and discussion}

Figure 1 shows that the rate of car exhaust suicides in the United States increased fairly steadily from about 6 per million of the population to about 11 per million in the mid-1960s; thereafter the rate gradually declined to about 9 per million in the 1980s. The rate for Britain was initially much lower than in the United States, at less than 1 exhaust suicide per million of the population in 1950 . Until 1970 , the rate increased gradually to about 3 per million; thereafter it increased much more rapidly so that it had surpassed the US rate in the late 1970 s, reaching nearly 17 per million in 1984.

The picture revealed by fig 1 is essentially consistent with the idea that emission controls in the United States have reduced the opportunity for suicide by car exhaust gases; the fact that the decline in these suicides began slightly before the introduction of nationwide controls probably reflects the earlier introduction of controls in some states and on some new cars. 


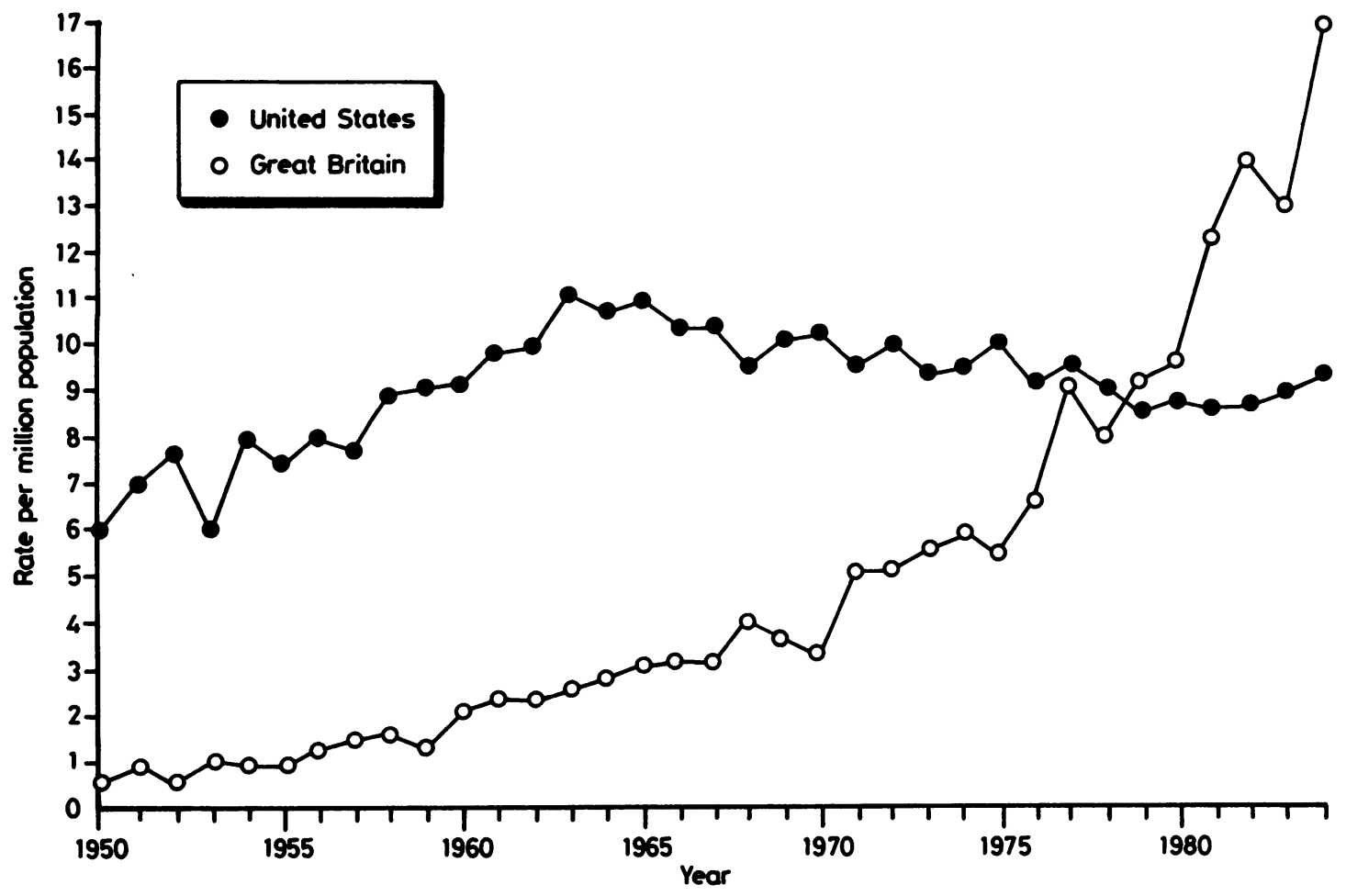

Fig 1 Rates of car exhaust suicide, United States and Britain, 1950-84.

However, fig 1 also raises some questions. In particular, why did the rate of exhaust suicides increase in the United States until the beginning of emission controls? And why did the similar steady increase of these suicides in Britain until the beginning of the 1970s greatly escalate thereafter?

Some light on the first of these questions is shed by fig 2, which shows US car exhaust suicides for 1950 to 1984 in relation to cars in operation and the "adjusted" measure of cars in operation. (Numbers of exhaust suicides are standardised against a population base for 1950.) As expected on the basis of an opportunity hypothesis, the increase in the number of car exhaust suicides matches closely the increase in numbers of cars in operation until the advent of emission controls in the mid-1960s. The fact that the subsequent rate of decline in exhaust suicides does not closely fit the decline in opportunities for these suicides as measured by the "adjusted" measure of cars in operation is more difficult to explain. A small part of the reason may be that between 1965 and 1984 the overall motivation to commit suicide may have increased, as reflected by an increase in the rate of suicide from 9.8 to 12.4 per 100000 . This may have served to increase the number of people attempting to kill themselves with exhaust gases. More important may be that the "adjusted" measure of cars in operation might exaggerate the reduction in opportunities for exhaust suicide. For example, in a nation of two-car families, many people owning a new car may also have access to a toxic pre-control model. Or it might be argued that, short of completely eliminating $\mathrm{CO}$ from car exhausts, the main effect of reducing $\mathrm{CO}$ concentrations would be to extend the period of exposure necessary to produce death: instead of taking perhaps as little as 15 minutes to die, as might be the case with "pre-control" models, ${ }^{11}$ potential suicide victims may have to inhale the exhaust fumes of newer cars for a matter of hours. But this would of itself decrease the rate of completed suicides by increasing the chances of intervention and, in any case, examples of failed suicides using car exhausts have recently appeared in the literature. Nevertheless, there do seem to be some reasons for suspecting the validity of the "adjusted" measure of cars in operation.

Leaving aside its inadequacies, there is another possible explanation for the poor fit between the "adjusted" measure of cars in operation and the reduction in number of exhaust suicides. This is suggested by consideration of data for Britain 
Toxicity of car exhausts and opportunity for suicide: comparison between Britain and the United States

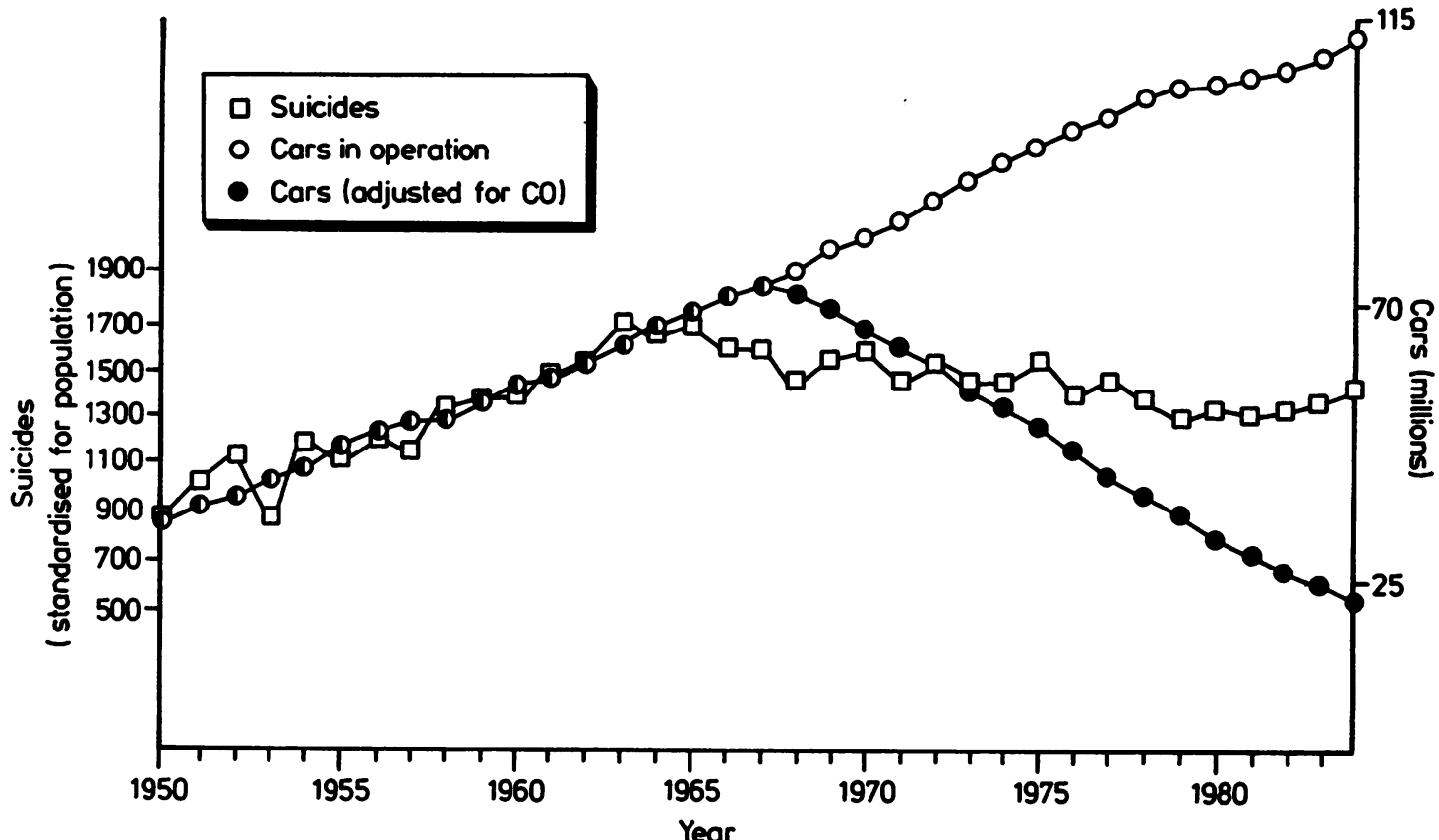

Fig 2 Exhaust suicides and cars in operation, United States, 1950-84.

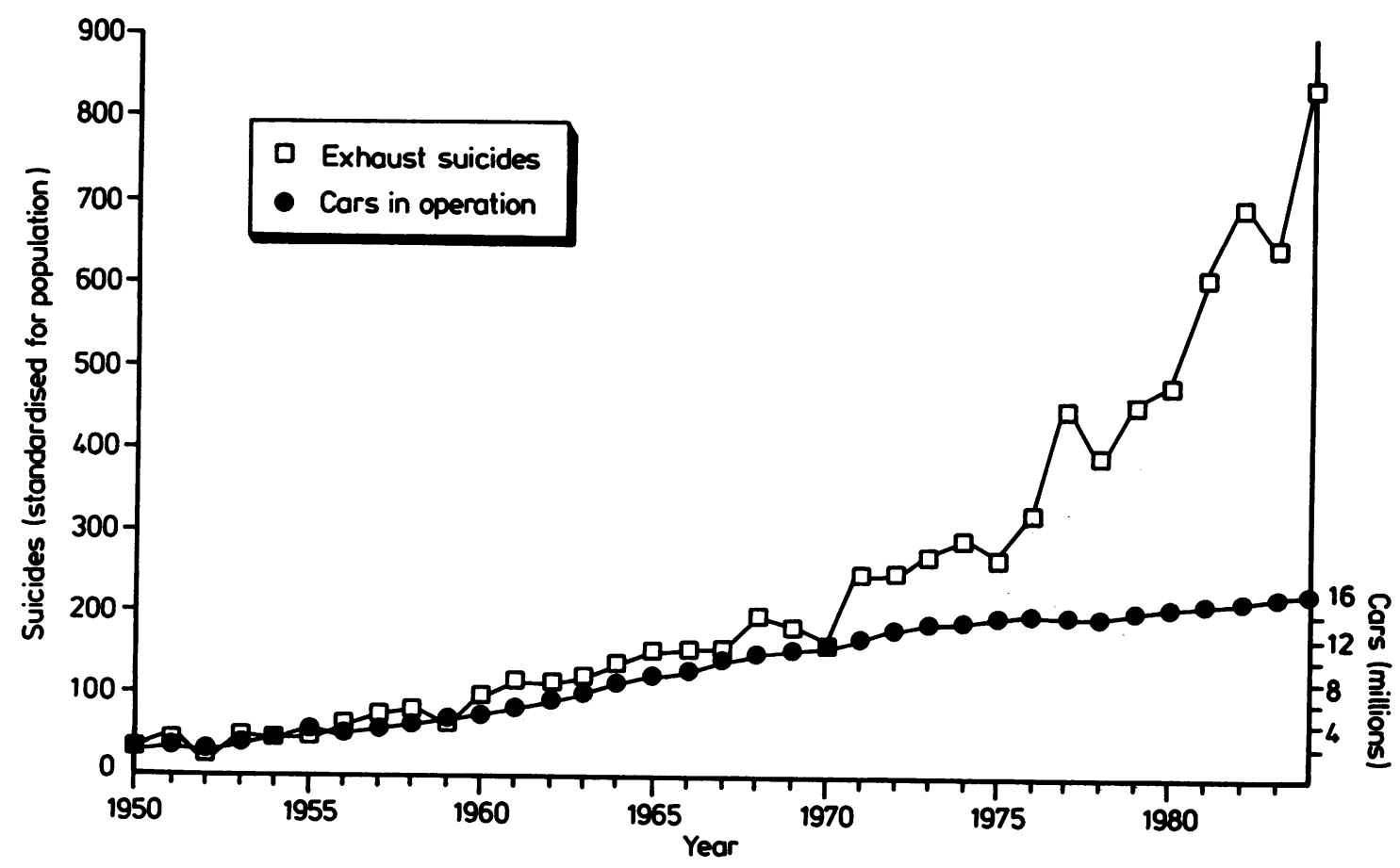

Fig 3 Car exhaust suicides and cars in use, Britain, 1950-84. 
presented in fig 3, which shows exhaust suicides (standardised for population against a 1950 base) in relation to cars in use. There is a close match between the two sets of data until the beginning of the 1970s when the increase in exhaust suicides begins to outstrip the increase in number of cars. This same phenomenon was observed by Bulusu and Alderson ${ }^{12}$ who suggested a number of possible explanations, including an increase in homes with garages and the increased popularity of estate and "hatchback" cars which require a shorter hose to let exhaust gases into the passenger compartment. While it seems unlikely that changes of this kind have been of sufficient magnitude to account for the greatly increased numbers of exhaust suicides, British data to test these ideas are not readily available. For what it is worth, however, some available US data are not supportive: according to the MVMA annual report for 1985 the proportion of new cars which were station wagons declined from $9.3 \%$ in 1969 to $5.7 \%$ in 1985 . The more likely explanation, also suggested by Bulusu and Alderson," is "the snowball effect of people discovering this (ie, exhaust gases) as an available method". While, again, no relevant data are available to test this idea, it does seem intuitively more plausible in explaining the greatly accelerated rate of increase in the use of this method. It is possible, also, that the "snowball" of increased knowledge might have been given a "hefty shove" in Britain by the detoxification of domestic gas. While little immediate displacement was observed to other methods following detoxification it is likely that in the longer term populations faced with a reduction of opportunities for suicide might gradually seek to expand the repertoire of alternative methods, especially of ones sharing some of the advantages of those whose availability had been reduced.

This suggests that a similar snowball effect of increased knowledge about car exhaust gases (even if not fuelled by an active search to replace methods no longer available) also occurred in the United States and that this served to increase the use of this method at the same time as emission controls were having the opposite effect-which, again, might account for the observed pattern since the mid-1960s in exhaust suicides. Some support for this idea is provided by fig 4, which shows rates of exhaust suicide per million cars in use for Britain and per million "adjusted" cars in operation for the United States. (Despite its deficiencies the "adjusted" measure seems intuitively to provide a better measure of opportunities for the United States than the unadjusted count of cars in

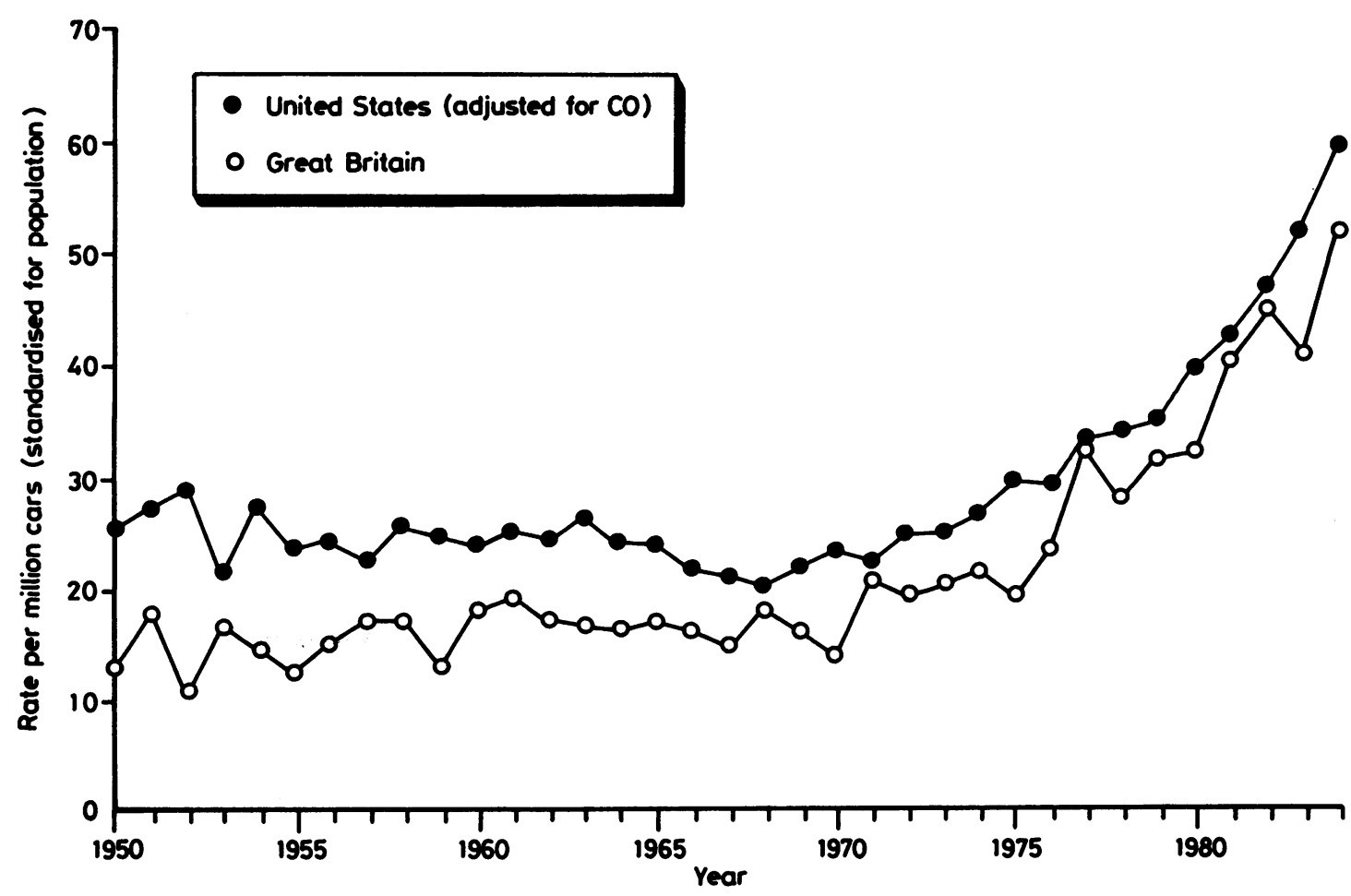

Fig 4 Car exhaust suicides per million cars, Britain and United States (US adjusted for CO) 1950-84. 
operation.) It can be seen that the two curves are highlycorrelated $(r=0.93, p<0.01)$, whichsuggeststhat the increases in both countries may have a similar cause. If this is an increase in knowledge about the method, the further question arises, why this should have occurred at roughly the same time in both countries. It is possible that Phillips' findings of an imitative element in suicide with, for example, rates of suicide increasing after a well publicised suicide death, ${ }^{13}$ may hold the explanation.

Accepting that emission controls in the United States appear to have reduced car exhaust suicides, the question then arises whether there was as little displacement to other methods as there appears to have been following detoxification of domestic gas in England and Wales. Given that both exhaust gas and domestic gas share many of the same advantages not possessed by other methods in terms of ease and lack of pain, it would not be surprising if this were the case. Unfortunately, available data do not permit an answer because car exhaust suicide always accounted for a much smaller proportion (about $10 \%$ ) of all suicides in the United States than did domestic gas in England and Wales. This would increase the difficulty of demonstrating the absence of displacement to other methods, especially given the steady rise in total numbers of suicides from 19041 in 1960 to 29286 in 1984. This rise may, of course, have been even greater had exhaust gases not been detoxified. Assuming no displacement (which is unlikely) and a greater propensity to use the method as a consequence of increased knowledge (for which there is only suggestive evidence), applying the suicide rate calculated on the basis of "adjusted" cars in operation to the actual numbers of cars for each year suggests that, at best, emission controls may have saved in the region of 48000 lives between 1968 and 1984, with additional expected savings in future years. This figure would be much lower-about 6500 - if there had been no greater propensity to use the method, and lower still if significant displacement had occurred; nevertheless, it might still represent a not insignificant saving of lives.

A final issue raised by the findings concerns the question why the ratio of car exhaust suicides to cars in use should, until the advent of emission controls, have been so much greater in the United States than in Britain, even though overall rates of suicide (calculated on a crude population base) did not differ much between the two countries (with 9.8 per 100000 of the population in the United States and 9.6 per 100000 in Britain in 1965). Part of the explanation may lie in differences in such factors (for which comparative data are not readily available) as numbers of garages or the mean toxicity of car exhausts. It is more likely that the difference reflects the disparity in car ownership between the two countries which, though still considerable (with one automobile in the United States for every $2 \cdot 1$ people in 1984 , compared with one car for every 3.4 people in Great Britain), was even greater in 1950 (US, one automobile per 4.2 people; GB, one car per 21.8 people). Any single United States citizen has therefore had access to a greater number of vehicles, which may have increased the probability of this method being selected. Related to this is the much greater salience of the automobile in the cultural consciousness and way of life-and, thus, possibly also of death-of the average US citizen.

\section{Conclusions}

The results of this study support the idea that emission controls have brought about a decrease in suicide by car exhaust gases in the United States. Because of the particular advantages of exhaust gas as a means of suicide, displacement to other methods is unlikely to have been complete and the savings in life may have been substantial. In Britain, where emission controls have yet to be introduced, the rate of exhaust suicides has greatly increased in recent years, possibly as a result of increased knowledge about this method. The British rate, as expressed per million of the population, is now much higher than in the United States though for many years previously it was much lower. While such evidence about suicide is hardly likely to swing the case for emission controls in Great Britain, it does suggest that devices to shut off the engine when $\mathrm{CO}$ levels rise to dangerous levels in the passenger compartment or impediments to connecting hoses to exhausts should be considered. More generally, this research provides further support for the idea that reducing opportunities for suicide may be a viable preventive strategy. ${ }^{14,15}$ Apart from the important example of the detoxification of domestic gas in England and Wales, which was estimated by the Office of Health Economics to have saved 6700 lives between 1963 and 1970, other examples are the lower risk of gun suicides in US states with stricter gun control laws 1617 and the reductions in self-poisonings following changes in prescribing practices for barbiturates in Australia. 8

Finally, it is clear that much more research is needed into the opportunity structure for suicide. Such research should not confine itself merely to quantification of physical opportunities because this study found only a moderate fit between exhaust suicides and the number of cars in use or the "toxicity" of the total vehicle population (which is another way of describing the "adjusted" measure of cars in operation in the United States). Also important in some instances may be the access to opportunities, as 
measured by the ratio of population to opportunities. If the conditions under which displacement takes place are to be understood, more will need to be discovered about levels of public knowledge concerning the different methods and how such knowledge is spread. In addition, attitudes to these methods of those who have, and have not, attempted to kill themselves will need to be tapped.

Information of this kind not only would contribute to theory by permitting better account to be taken of situational influences upon suicidal motivation, but is also an essential requirement for the development of adequate opportunity-reducing preventive measures.

We are grateful to Mrs Pat Mayhew, of the Home Office Research and Planning Unit, London, and to Dr Peter Jones, of the Department of Criminal Justice, Temple University, for their assistance and advice.

\section{References}

${ }^{1}$ Hassall C, Trethowan WM. Suicide in Birmingham. $\mathrm{Br}$ Med J 1972; 717-8.

${ }^{2}$ Kreitman N. The coal gas story. United Kingdom suicide rates, 1960-71. Br J Prev and Soc Med 1976; 30: 86-93.

${ }^{3}$ Kreitman N, Platt S. Suicide, unemployment, and domestic gas detoxification in Britain. J Epidemiol Comm Hlth 1984; 38: 1-6.
${ }^{4}$ Low AA, Farmer RDT, Jones DR, Rohde JR. Suicide in England and Wales: an analysis of 100 years, 1876-1975. Psychol Med 1981; 11: 359-68.

${ }^{5}$ Bagley C. The evaluation of a suicide prevention scheme by an ecological method. Soc Sci Med 1968; 3: 1-14.

6 Bagley CR. Suicide prevention by the Samaritans. Lancet 1977; ii: 348-9.

${ }^{7}$ Barraclough BM, Jennings C, Moss JR. Suicide prevention by the Samaritans: a controlled study of effectiveness. Lancet, 1977; ii: 237-9.

${ }^{8}$ Sainsbury P, Jenkins J, Levey A. The social correlates of suicide in Europe. In: Farmer R, Hirsh S. eds. The suicide syndrome. London: Crown Helm, London 1980.

9 Landers D. Unsuccessful suicide by carbon monoxide. West J Med 1981; 135: 360-3.

${ }^{10}$ Hay P, Bornstein R. Failed suicide by emission gas poisoning. Am J Psychiat 141: 592-3.

11 McBay AT. Carbon monoxide poisoning. (Law-Medicine Notes) N Engl J Med 1965; 272: 252-3.

12 Bulusu L, Alderson M. Suicides 1950-82. Population Trends 35: 1984; London: HMSO.

${ }^{13}$ Phillips DP. The influence of suggestion on suicide. Am Soc Rev 1974; 39: 340-54.

14 Seiden RH. Suicide prevention: a public health/public policy approach. Omega $1977 ; 8(3)$ : 267-76.

${ }^{15}$ Brown JM. Suicides in Britain. More attempts, fewer deaths, lessons for public policy. Arch Gen Psychiat 1979; 36: 1119-24.

${ }^{16}$ Lester D, Murrell ME. The influence of gun control laws on suicidal behaviour. Am J Psychiat 1980; 137(1): 121-2.

${ }^{17}$ Lester D, Murrell ME. The preventive effect of strict gun control laws on suicide and homicide. Suicide and Life Threatening Behaviour 1982; 12: 131-40.

18 Oliver RG, Hetzel BS. An analysis of recent trends in suicide in Australia. Int J Epidemiol 1973; 2: 91-101. 